\title{
LINC00958 promotes bladder cancer carcinogenesis by targeting miR-490-3p and AURKA
}

\author{
Hongtao Zhen ${ }^{*}$, Peng $\mathrm{Du}^{2}$, Qiang $\mathrm{Yi}^{1}$, Xiaolong Tang ${ }^{1}$ and Tongqing Wang ${ }^{1}$
}

\begin{abstract}
Background: Bladder cancer is a prevalent malignancy of the urinary system, in which long non-coding RNAs (IncRNAs) are highly associated. We aimed to elucidate the role of LINC00958 in bladder cancer.

Methods: LINC00958 expression levels were measured using qRT-PCR. The interaction of LINC00958-miR-490-3pAURKA was analyzed by luciferase, RIP, and RNA pull-down assays. The biological roles of LINC00958, miR-490-3p, and AURKA in bladder cancer cells were analyzed using CCK8, BrdU, and transwell assays.

Results: Increased expression of LINC00958 and AURKA was observed in bladder cancer tissues and cell lines. Decreased LINC00958 expression repressed bladder cancer progression and downregulation of miR-490-3p accelerated bladder cancer cell progression. Moreover, LINC00958 sponges miR-490-3p to upregulate AURKA expression, thereby promoting carcinogenesis in bladder cancer cells.

Conclusions: Our study revealed that LINC00958 facilitated cell proliferation and invasion, and suppressed cell apoptosis by sponging miR-490-3p and upregulating AURKA, thus inspiring a new treatment method for bladder cancer.
\end{abstract}

Keywords: LINC00958, miR-490-3p, AURKA, Bladder cancer

\section{Background}

Bladder cancer is the most prevalent malignancy of the urinary system, with a 3\% incidence and $2.1 \%$ death rate worldwide [1]. Despite improvements in the current diagnosis and treatment of bladder cancer, drug resistance leads to a high recurrence rate $[2,3]$. Therefore, it is essential to understand how bladder cancer develops and identify more effective targets for the treatment and prognosis of bladder cancer patients.

Long non-coding RNAs (lncRNAs) are non-coding RNAs containing over 200 nucleotides, which are key modulators of tumorigenesis [4-6]. LncRNAs have been

\footnotetext{
* Correspondence: hongtaozhen23@163.com

'Department of Urology Ward 1, Zhengzhou Central Hospital Affiliated to

Zhengzhou University, No. 195 Tongbai Road, Zhongyuan District, Zhengzhou 450007, Henan, China

Full list of author information is available at the end of the article
}

shown to participate in a variety of tumor pathological processes by inhibiting miRNAs to upregulate the expression of their target genes [7] [8-10]. Long intergenic nonprotein coding RNA 958 (LINC00958) is affiliated with the lncRNA class and is involved in cell growth, migration, and metastasis in some cancers, such as cervical, lung, and gastric cancer [11-13]. For instance, LINC00958 modulates cell sensitivity to radiotherapy by inhibiting miRNA5095 and upregulating RRM2 expression in cervical cancer [11]. In bladder cancer, only one study has suggested that LINC00958 facilitated the pathological process of bladder cancer by repressing miR-378a-3p and elevating IGF1R expression [14]. Nevertheless, the regulation of IncRNAs in cancers is a complex process, and there may be other downstream factors of LINC00958 involved in the progression of bladder cancer that need further study.

C C The Author(s). 2021 Open Access This article is licensed under a Creative Commons Attribution 4.0 International License, which permits use, sharing, adaptation, distribution and reproduction in any medium or format, as long as you give appropriate credit to the original author(s) and the source, provide a link to the Creative Commons licence, and indicate if changes were made. The images or other third party material in this article are included in the article's Creative Commons licence, unless indicated otherwise in a credit line to the material. If material is not included in the article's Creative Commons licence and your intended use is not permitted by statutory regulation or exceeds the permitted use, you will need to obtain permission directly from the copyright holder. To view a copy of this licence, visit http://creativecommons.org/licenses/by/4.0/ The Creative Commons Public Domain Dedication waiver (http://creativecommons.org/publicdomain/zero/1.0/) applies to the data made available in this article, unless otherwise stated in a credit line to the data. 
miRNAs are non-coding RNAs of approximately 20 nucleotides, which typically function by degrading the expression of their target genes [15]. Dysregulation of miRNAs has been regarded as a critical factor in cancer cell growth and apoptosis in cancers such as colon, ovarian, and lung cancer [16-18]. Both miR-490-3p and miR-490-5p are members of the miR-490 family, which participate in tumorigenesis $[19,20]$. Evidence has shown that miR-490-3p prevents cell growth and invasion, whereas it increases apoptosis in various cancers, such as prostate cancer [21], esophageal squamous cell carcinoma [22], and breast cancer [23]. Several studies have suggested the inhibitory action of miR-490-5p in bladder cancer [24-26]; however, no study has explored the molecular mechanism of miR-490-3p in the development of bladder cancer.

The aurora kinase A (AURKA) gene is located on chromosome 20q13.2 and consists of 12 exons. It encodes a cell cycle-regulated kinase that participates in microtubule formation [27, 28]. High-throughput data analysis demonstrated that AURKA was identified as a tumor promoter in all types of cancers [29-31]. Upregulation of AURKA has been reported in bladder cancer progression, which might be a potential therapeutic target for bladder cancer [32-34]. For example, overexpression of AURKA accelerated cell proliferation and reduced cell apoptosis, and high AURKA expression predicted poor prognosis in bladder cancer [33]. Furthermore, miRNA-124-3p inhibited cell proliferation and migration, but enhanced cell apoptosis by reducing AURKA in bladder cancer [35]. Nonetheless, the effect of LINC00958 and miR-490-3p on AURKA remains unknown.

In this study, we sought to determine the role of the LINC00958-miR-490-3p-AURKA axis in bladder cancer. We hypothesized that LINC00958 aggravates bladder cancer progression via the miR-490-3p-AURKA axis.

\section{Methods}

\section{Samples and cells}

Cancer tissues and adjacent normal tissues from 34 patients with bladder cancer, who provided informed written consent, were obtained from our hospital. The study was approved by the ethics committee of our hospital. The clinicopathological characteristics of the patients are listed in Table 1. Human bladder cancer cell lines (5637, RT4, T24, and UMUC3) and a normal human ureteral epithelial cell line (SV-HUC-1) were purchased from ATCC (Manassas, VA, USA). 5637 and UMUC3 cells were cultured in RPMI-1640 medium (Gibco, Waltham, MA, USA), RT4 and T24 cells were cultured in McCoy's 5A medium (Gibco), and SV-HUC-1 cells were cultured in Ham's F-12 K medium (Gibco) with $10 \%$ FBS (Gibco) at $37^{\circ} \mathrm{C}$ with $5 \% \mathrm{CO}_{2}$.
Table 1 Clinicopathological characteristics of bladder cancer

\begin{tabular}{ll}
\hline Clinicopathological characteristics & $\mathbf{N}(\%)$ \\
\hline Total & 34 \\
Age (year) & \\
$>60$ & $19(55.88)$ \\
$\quad \leq 60$ & $15(44.12)$ \\
Sex & \\
Male & $27(79.41)$ \\
Female & $7(20.59)$ \\
Smoking & \\
Yes & $16(47.06)$ \\
No & $18(52.94)$ \\
Grading & \\
G1 & $8(23.53)$ \\
G2 & $13(38.24)$ \\
G3 & $11(32.35)$ \\
G4 & $1(2.94)$ \\
n.a. & $1(2.94)$ \\
Tumor size (cm) & \\
$<3$ & $15(44.12)$ \\
$\geq 3$ & $19(55.88)$ \\
Tumor number & \\
1 & $23(67.65)$ \\
2-7 & $26(76.47)$ \\
Not specified & $5(14.71)$ \\
\hline
\end{tabular}

\section{RT-qPCR}

Trizol reagent (Cat\#: 15596018, Thermo Fisher Scientific, Waltham, MA, USA) was used to extract mRNA and IncRNA. The miRcute miRNA extraction kit (DP501, Tiangen, Beijing, China) was used for miRNA extraction. The PrimeScript First Strand cDNA Synthesis kit (RR037A, Takara, China) was used to convert mRNA and lncRNA to cDNA. The All-in-One miRNA First Stand cDNA Synthesis Kit (AMRT-0060, GeneCopoeia, Rockville, MD, USA) was used to convert miRNA into cDNA. Finally, RT-qPCR was performed on the ABI 7500 Sequence Detection System with SYBR Premix Ex Taq (RR420A, Takara, China) for mRNA and lncRNA, and All-in-One miRNA qRT-PCR Detection Kit (AOMD-Q050, GeneCopoeia) for miRNA. The quantification of LINC00958 and AURKA relative to GAPDH, and miR-490-3p relative to U6 was performed using the formula $2^{-\Delta \Delta \mathrm{Ct}}$. All primers are listed in Table 2. 
Table 2 Primer sequences of qRT-PCR

\begin{tabular}{ll}
\hline Genes & Primer sequences \\
\hline LINC00958 & F:5'-AGAAGGAGGAGAAGCAA-3' \\
& R:5'-TGTGAAGTGGAGGGAGGA-3' \\
miR-490-3p & F:5'-TGCGGTTCAAGTAATTCAGGA-3' \\
& R:5'-CCAGTGCAGGGTCCGAGGT-3' \\
AURKA & F:5'-GGAATATGCACCACTTGGAACA-3' \\
& R:5'-TAAGACAGGGCATTGCCAAT-3' \\
GAPDH & F:5'-CATGAGAAGTATGACAACAGCCT-3' \\
& R:5'-AGTCCTTCCACGATACCAAAGT-3' \\
U6 & F:5'-GTGCTCGCTTCGGCAGCACATATAC-3' \\
& R:5'-AAAAATATGGAACGCTTCACGAATTG-3' \\
\hline
\end{tabular}

\section{Subcellular localization}

The PARIS Kit (AM1921, Life biosciences, Boston, MA, USA) was used to extract the subcellular fractionation for the LINC00958 localization experiment. After obtaining the nuclear and cytoplasmic fractions, we detected the LINC00958 level in the nucleus and cytoplasm by RT-qPCR, where GAPDH was used as the internal control of the cytoplasmic fraction and U6 was used as the internal control of the nuclear fraction.

\section{Cell transfection}

SiRNA LINC00958 (Si-lnc), miR-490-3p mimics, miR490-3p inhibitor, SiRNA-AURKA, and the corresponding negative control (NC) were purchased from RiboBio (Guangzhou, China). RT4 and T24 cells were cultured in 24-well plates $\left(2 \times 10^{5}\right.$ cells $)$, and the plasmids with the final concentration of $50 \mathrm{nM}$, and $2 \mu \mathrm{l}$ Lipofectamine 2000 (Invitrogen, Waltham, MA, USA) were added to the plates. After $48 \mathrm{~h}$ of incubation, the following experiments were performed.

\section{CCK8 assay}

The CCK8 kit (Cat\#: K1018; APExBIO, China) was used. RT4 and T24 cells $\left(4 \times 10^{4}\right.$ cells) were cultured in 96well plates. After 24, 48, 72, and $96 \mathrm{~h}$ of transfection, $10 \mu \mathrm{L}$ of CCK8 solution was added to each well and incubated for $2 \mathrm{~h}$. Finally, the OD values were quantified using a multimode plate reader at $450 \mathrm{~nm}$ (Thermo Fisher Scientific).

\section{BrdU assay}

BrdU Cell Proliferation ELISA kit (Cat\#: ab126556, Abcam, UK) was used to perform the BrdU assay. RT4 and T24 cells $\left(2 \times 10^{5}\right.$ cells) were seeded into 96-well plates, which were then labeled with $20 \mu \mathrm{L}$ BrdU for 12 $\mathrm{h}$ to incorporate BrdU into the proliferating cells. Following this, cells were fixed with a fixing solution and DNA was denatured. The cells were incubated with BrdU primary antibody for $1 \mathrm{~h}$ at $25^{\circ} \mathrm{C}$ and then with the secondary antibody for $1 \mathrm{~h}$ at $25^{\circ} \mathrm{C}$. Finally, TMB solution was added to each well. After the color developed, the stop solution was added to each well. The OD value $(450 \mathrm{~nm})$ was quantified using a multimode plate reader (Thermo Fisher Scientific).

\section{Transwell assay}

Transwell chambers (Cat\#: \#3244, Corning Inc., Corning, NY, USA) with $8 \mu \mathrm{m}$ pores were precoated with Matrigel $(2 \mu \mathrm{g} /$ well, BD Biosciences, Franklin Lakes, NJ, USA) on the top side of the insert membrane in a 24well plate. To the lower chamber, $600 \mu \mathrm{L}$ of $5 \%$ FBS cell culture medium was added, and the upper chamber was seeded with $200 \mu \mathrm{L}$ serum-free RT4 and T24 cell suspensions $\left(5 \times 10^{4}\right.$ cells $)$ and incubated for $24 \mathrm{~h}$. The unattached cells were then cleaned using cotton swabs. The inserts were immobilized in methanol. After fixation, 1\% crystal violet (C0775, Sigma-Aldrich, St. Louis, MO, USA) was used for dyeing (30 min). Finally, cells at the bottom of the membrane in each chamber were counted under a microscope (Olympus, Tokyo, Japan).

\section{Dual luciferase reporter assay}

The psiCHECK2 LINC00958 wild-type vector and psiCHECK2 AURKA 3'UTR wild-type vector containing the miR-490-3p binding sites, psiCHECK2 LINC00958 mutated vector, and psiCHECK2 AURKA 3'UTR mutated vector without the miR-490-3p binding sites were constructed by GenePharma (Shanghai, China). RT4 and T24 cells were cultured in 24-well plates $\left(2 \times 10^{5}\right.$ cells), and the cells were co-transfected with negative control (NC) or miR-490-3p mimic using Lipofectamine 3000 (Invitrogen). After $72 \mathrm{~h}$ of incubation, the Dual-Luciferase Reporter Assay System was used (Cat\#: E1910, Promega, San Luis Obispo, CA, USA) to detect firefly and renilla luciferase activities. The firefly activity was normalized to the renilla activity.

\section{RIP assay}

The Magna RIP RNA-binding protein immunoprecipitation kit (Cat\#: 17-700, Millipore, Burlington, MA, USA) was used to detect the interaction between LINC00958 and miR-490-3p. The prepared cell lysates of RT4 and T24 cells transfected with miR-490-3p mimic or NC mimic were immunoprecipitated with magnetic beads conjugated with Ago2 (Cat\#: ab186733, Abcam) or the control IgG (Cat\#: ab172730, Abcam) for $4 \mathrm{~h}$ at $4{ }^{\circ} \mathrm{C}$. Finally, the precipitates were collected, and the enrichment of LINC00958 was subjected to RT-qPCR.

\section{RNA pull-down analysis}

The RT4 and T24 cells were transfected with biotinlabeled miR-490-3p (Bio-miR-490-3p) and biotin-labeled negative control (Bio-NC) (RiboBio) for $24 \mathrm{~h}$. Following 
this, cell lysates were obtained and incubated with streptavidin beads (Cat\#: \#88817, Thermo Fisher Scientific) for $2 \mathrm{~h}$ at $25^{\circ} \mathrm{C}$. Then, the bound RNAs were eluted and purified using the RNeasy Mini Kit (Cat\# 74104, Qiagen, Germany). Finally, AURKA expression was determined using RT-qPCR.

\section{Western blotting (WB) analysis}

Whole-cell lysates of RT4 and T24 cells were treated with RIPA buffer (Cat\#: \#20-188, Sigma-Aldrich). Then, $30 \mu \mathrm{g}$ of proteins were separated on 12\% SDS-PAGE gels and transferred to PVDF membranes. After blocking with 5\% BSA in TBST and washing twice with TBST, the membranes were incubated with anti-Bax (1:1000, Cat\#: \#ab32503, Abcam), anti-Bcl-2 (1:1000, Cat\#: \#ab32124, Abcam), anti-AURKA (1:1000, Cat\#: \#14475, Cell Signaling Technology (CST), Danvers, MA, USA), and anti-GAPDH (1:2000, Cat\#: \#5174, CST) antibodies overnight at $4{ }^{\circ} \mathrm{C}$. Then, the membranes were incubated with the secondary antibody anti-HRP rabbit (1:10000, Cat\#: 7074, CST) for $1 \mathrm{~h}$. ECL reagents (P0018S, Beyotime, China) were used to obtain protein bands. The relative expression of AURKA was normalized to GAPD $\mathrm{H}$ and analyzed using the Image Lab software (Bio-Rad, Hercules, CA, USA).

\section{Statistical analysis}

Student's t-test for two groups and one-way analysis of variance (ANOVA) for multiple group comparisons were performed using GraphPad Prism 8.0 (GraphPad Prism, USA). Pearson's correlation analysis was used to detect the association between LINC00958 and miR-490-3p or AURKA and miR-490-3p. $P<0.05$ was considered statistically significant. Data are shown as mean \pm standard deviation (SD).

\section{Results}

The selection of LINC00958-miR-490-3p-AURKA axis as our study object

LINC00958 has been extensively studied in some cancers such as head and neck cancers [36-38], gastric cancer [13], lung cancer [12], and cervical cancer [11, 39]. It is also a potential oncogenic factor and a candidate prognostic biomarker in bladder cancer $[40,41]$ and is associated with lymphangiogenesis and lymphatic metastasis [42]. Only Cui et al. reported LINC00958 in a ceRNA network in bladder cancer [14]. Thus, LINC00958 has been rarely studied in bladder cancer. To expand the downstream network of LINC00958, we first analyzed the GSE40355 and GSE37815 data series to identify differentially expressed miRNAs (DE-miRs) and differentially expressed mRNAs (DE-mR) in bladder cancer samples. By intersecting the predicted target miRNAs of LINC00958 using starBase and the DE-miR list (adjusted $P<0.05, \log F C \leq-$
1.5), we identified miR-490-3p (Fig. 1A). The cancersuppressive role of $\mathrm{miR}-490-3 \mathrm{p}$ has been demonstrated in various cancers [43-46], but has not been studied in bladder cancer. Thus, we speculated that LINC00958 promotes bladder cancer malignancy by suppressing miR490-3p. We sought to identify the potential downstream network of LINC00958-miR-490-3p. By intersecting the DE-mR list of GSE37815 $(P<0.05, \operatorname{logFC} \geq 1.5)$ and the target mRNAs of miR-490-3p predicted by TargetScan (version 7.2 of human database), we identified AURKA (Fig. 1B). AURKA has also been reported to be a significant facilitator in bladder cancer [33, 34] and has been studied in miRNA-mRNA interaction networks [35]. However, AURKA has not been previously studied in a ceRNA network involving an lncRNA in bladder cancer. Thus, we hypothesized that AURKA might be regulated by LINC00958-miR-490-3p, thereby affecting the malignant phenotypes of bladder cancer.

\section{LINC00958 is upregulated in bladder cancer tissues and cells}

To analyze the biological function of LINC00958 in bladder cancer, LINC00958 expression in bladder cancer tissues and cells was first determined, which was dramatically elevated 4-fold in bladder cancer tissues compared to normal tissues (Fig. 2A). Furthermore, we also analyzed the correlation between LINC00958 expression and certain clinical parameters such as sex, age, smoking, tumor size, tumor grade, tumor number, and pathological $\mathrm{T}$ stage, and found that increased LINC00958 expression was correlated with tumor grade $(P=0.020)$ and pathological $\mathrm{T}$ stage $(P=0.039)$ in bladder cancer (Table 1$)$. LINC00958 expression in bladder cancer cell lines (5637, RT4, T24, and UMUC3) was significantly elevated by more than 2-fold compared to that in the normal human ureteral epithelium cell line (SV-HUC-1). Notably, the RT4 and T24 cell lines showed the highest LINC00958 expression; thus, we chose them for subsequent experiments (Fig. 2B). Next, we observed that $60 \%$ of LINC00958 was localized in the cytoplasm, while $40 \%$ of LINC00958 was found in the nucleus, suggesting that LINC00958 mainly exists in the cytoplasm (Fig. 2C). Then, we transfected siRNA-LINC00958 (Si-lnc) and negative control (NC) into RT4 and T24 cells and confirmed the silencing efficiency. As displayed in Fig. 2D, LINC00958 expression was reduced by over $50 \%$ in the Si-lnc groups compared to that in the blank groups of RT4 and T24 cells. These results indicated that LINC00958 was upregulated in bladder cancer tissues and cells.

\section{LINC00958 enhances the progression of bladder cancer cells}

To investigate whether LINC00958 plays a key role in bladder cancer, we performed a series of experiments in 


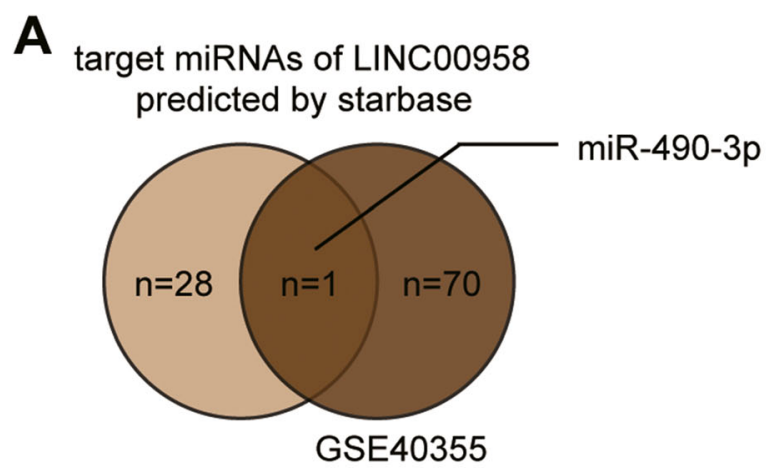

adjusted $\mathrm{P}<0.05, \log \mathrm{FC}<=-1.5$
B

target mRNAs of miR-490-3p

predicted by targetscan

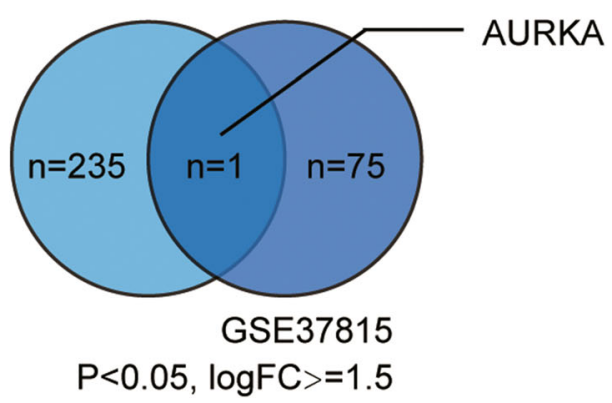

Fig. 1 The identification of miR-490-3p and AURKA as the downstream network players of LINC00958. A A Venn diagram showing the intersection of the predicted target miRNAs of LINC00958 by starbase (http://starbase.sysu.edu.cn/) and the differentially expressed miRNAs of GSE40355 (selection criteria: adjusted $P<0.05$, logFC $\leq-1.5$ ). B A Venn diagram showing the intersection of the target mRNAs of miR-490-3p predicted by targetscan (version 7.2 of human database) and the differentially expressed mRNAs of GSE37815 (selection criteria: adjusted $P<0.05$, logFC $\geq 1.5$ )

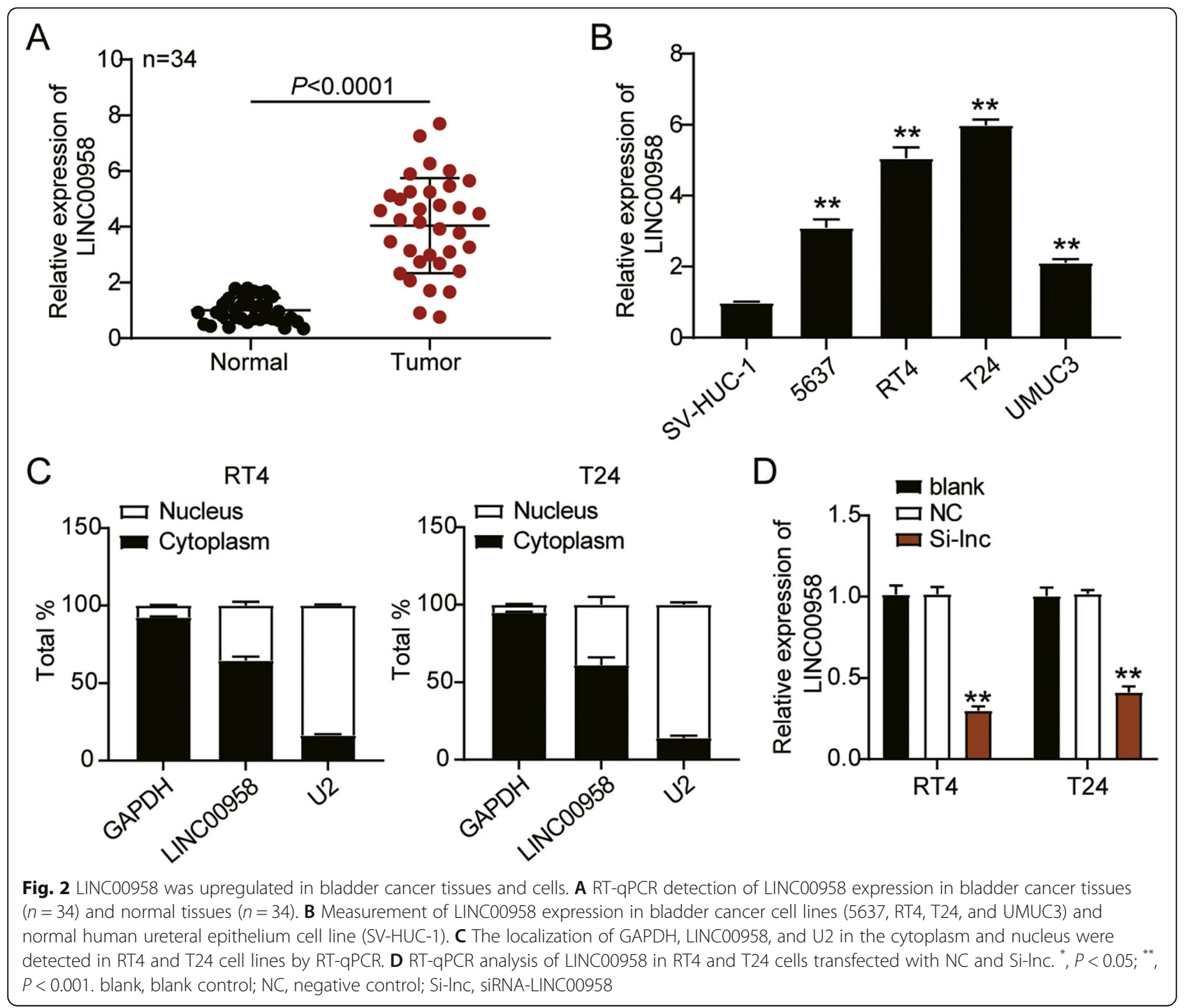


cells transfected with Si-lnc. The CCK8 assay showed that the cell viability levels in the $\mathrm{Si}$-lnc group were significantly lower than those in the blank group of both RT4 and T24 cells (Fig. 3A). Meanwhile, the BrdU assay showed that cell proliferation levels in the Si-lnc group were dramatically decreased by $50 \%$ compared to that in the blank groups of RT4 and T24 cells (Fig. 3B). Subsequently, we checked the invasion ability of the cells; cell invasion levels in Si-lnc group were significantly downregulated by $80 \%$ in the RT4 cells and by $50 \%$ in the T24 cells compared to that in the blank group (Fig. 3C). Moreover, the expression of the pro-apoptotic protein
Bax was dramatically increased in the Si-lnc group compared to the blank group of RT4 and T24 cells, while the anti-apoptotic protein $\mathrm{Bcl}-2$ showed the opposite tendency (Fig. 3D). Thus, these results indicate that LINC00958 enhances cell proliferation and invasion, but suppresses apoptosis of bladder cancer cells.

\section{LINC00958 sponges miR-490-3p in bladder cancer cells}

Next, we determined the interaction between LINC00958 and miR-490-3p. The binding site sequences of LINC00958 and miR-490-3p were predicted using starBase (Fig. 4A). Next, we detected the interaction by

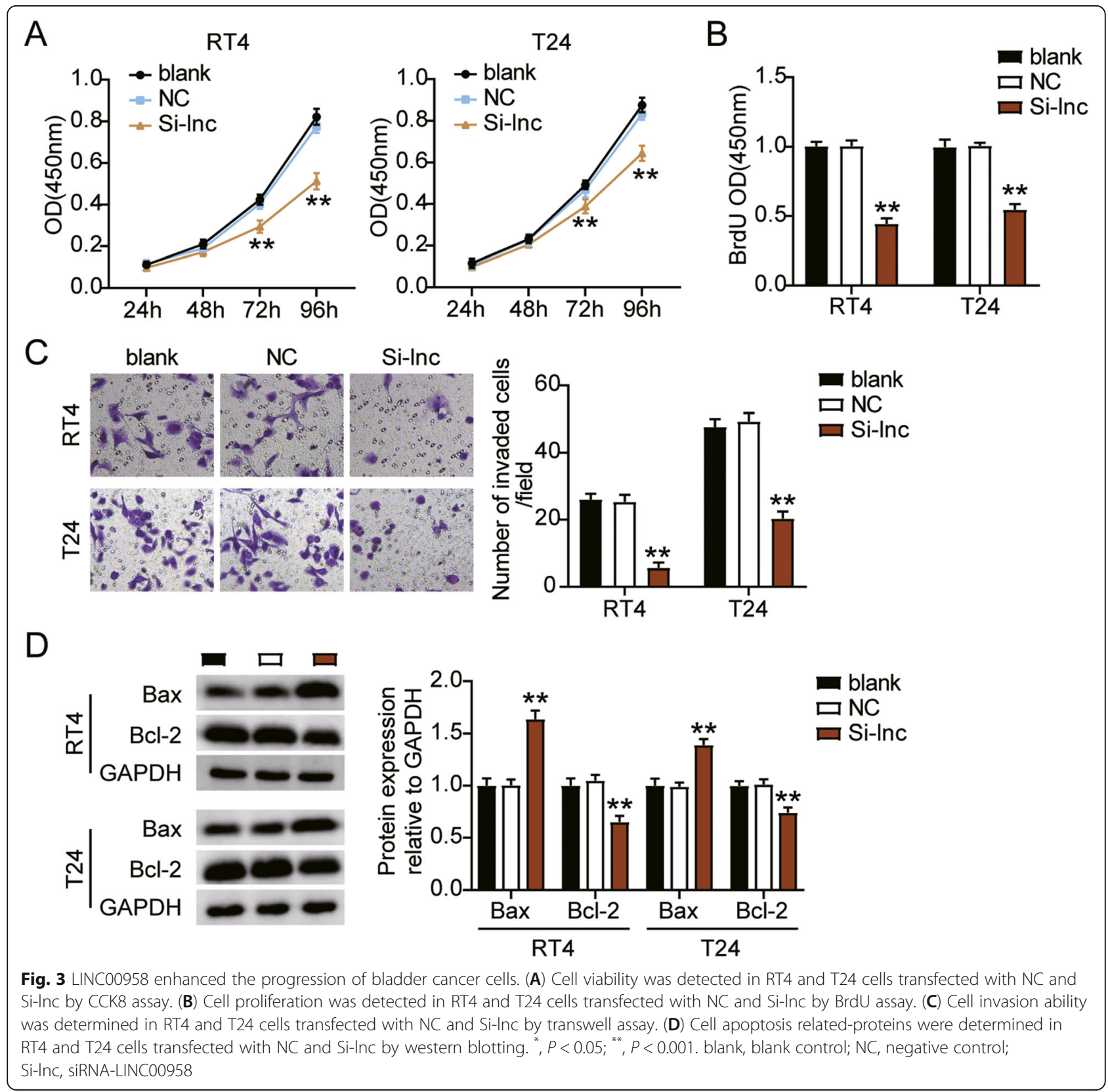


luciferase activity assay, where the miR-490-3p mimics or negative control (NC), and psiCHECK2 LINC00958-wide type (lnc-WT) or psiCHECK2 LINC00958 mutant (lncMUT) were co-transfected into RT4 and T24 cells. The results showed that only the co-transfection of miR-490$3 \mathrm{p}$ mimic and lnc-WT group showed a $50 \%$ decrease in luciferase activity, suggesting that miR-490-3p indeed interacts with LINC00958 (Fig. 4B). We also found elevated levels of LINC00958 in cells overexpressing miR-490-3p by interacting with AGO2, suggesting that LINC00958 had coordinated with miR-490-3p in both RT4 and T24 cells (Fig. 4C). Additionally, as shown in Fig. 4D, we observed that the miR-490-3p expression was 50\% lower in bladder cancer tissues than in adjacent normal tissues, and there was a negative correlation between LINC00958 and miR-490-3p levels in bladder cancer tissues (Fig. 4E). Furthermore, the miR-490-3p levels in RT4 and T24 cells were downregulated by over $50 \%$ compared to that in SVHUC-1 cells (Fig. 4F). We further transfected siRNALINC00958 (Si-lnc), negative control (NC), and miR-4903 p inhibitor into RT4 and T24 cells. We found that the miR-490-3p level in the inhibitor groups was 70\% lower than that in the blank groups; silencing LINC00958 led to a 1.5-fold increase in miR-490-3p levels and the miR-490$3 p$ levels in the Si-lnc + inhibitor groups were similar to those in the blank groups (Fig. 4G). Thus, miR-490-3p is a downstream gene of LINC00958 in bladder cancer cells.

\section{LINC00958 sponging miR-490-3p facilitates progression of bladder cancer}

We further assessed whether LINC00958 regulates miR-490-3p to affect the progression of bladder cancer. First, we found that the cell viability in the miR490-3p inhibitor group was significantly increased, while the cell viability in the Si-lnc + inhibitor group was similar to the blank group of both RT4 and T24 cells (Fig. 5A). In addition, cell proliferation in the miR-490-3p inhibitor group was elevated by 1.5 -fold, while the cell proliferation in the $\mathrm{Si}$-lnc + inhibitor group was similar to that in the blank group (Fig. $5 \mathrm{~B})$. Furthermore, the results of the transwell invasion assay showed that the cell invasion level in the miR490-3p inhibitor group was significantly enhanced in RT4 and T24 cells, while the Si-lnc + inhibitor group presented an invasion level similar to that of the blank group of both RT4 and T24 cells (Fig. 5C). Moreover, cell apoptosis presented by the expression of pro-apoptotic protein Bax was significantly reduced in the miR-490-3p inhibitor group, while the Bax expression level in the $\mathrm{Si}$-lnc + inhibitor group was similar to that of the blank groups of RT4 and T24 cells (Fig. 5D). Collectively, LINC00958 sponging miR-490$3 \mathrm{p}$ facilitates bladder cancer cell progression.

\section{MiR-490-3p targets AURKA in bladder cancer cells}

Subsequently, we sought to elucidate the interaction between miR-490-3p and AURKA. The binding site sequences of AURKA and miR-490-3p were predicted by TargetScan 7.2 (Fig. 6A). We further confirmed the interaction by luciferase activity assay, which showed that the co-transfection of miR-490-3p mimics and psiCHECK-2 AURKA 3'UTR WT plasmid showed a $50 \%$ decrease in luciferase activity compared to the NC groups, suggesting that miR-490-3p had a direct interaction with AURKA (Fig. 6B). Next, an RNA pull-down assay confirmed that miR-490-3p could bind to AURKA (Fig. 6C). In addition, miR-490-3p levels were enhanced by 3 -fold in the tumor tissues compared to the normal tissues (Fig. 6D), and were negatively correlated with AURKA in bladder cancer tissues (Fig. 6E). Moreover, miR-490-3p was upregulated by approximately 3-fold in RT4 and T24 cells compared to SV-HUC-1 cells (Fig. 6F). Next, we treated RT4 and T24 cells with siRNAAURKA (Si-AURKA), miR-490-3p inhibitor (inhibitor), and negative control (NC) to study the role of AURKA in bladder cancer. The siRNA-AURKA groups showed a 30\% decrease in AURKA protein expression, while the AURKA protein expression in the inhibitor group was increased by nearly 1.3 -fold when compared to that in the blank group. The levels observed in the Si-AURKA+ inhibitor groups were similar to those in the blank groups (Fig. 6G). Taken together, it can be concluded that miR-490-3p directly targets AURKA in bladder cancer cells.

\section{MiR-490-3p targeting AURKA hampers bladder cancer cells progression}

We further confirmed the biological action of miR-490$3 p$ on AURKA in bladder cancer. First, we found that cell viability in the siRNA-AURKA group was dramatically impaired, while the cell viability in the Si-AURKA+ inhibitor group was similar to that in the blank groups of both RT4 and T24 cells (Fig. 7A). Additionally, cell proliferation in the siRNA-AURKA group decreased by $30 \%$, while no significant difference was observed between the Si-AURKA+inhibitor group and blank groups in both RT4 and T24 cells (Fig. 7B). Moreover, the transwell invasion assay showed that cell invasion levels in the siRNA-AURKA group were decreased by $80 \%$ in the RT4 and $50 \%$ in the T24 cells, while the Si-AURKA+ inhibitor groups displayed similar cell invasion levels to blank groups in both RT4 and T24 cells (Fig. 7C). Finally, cell apoptosis levels in the siRNA-AURKA groups, indicated by the expression of the pro-apoptotic protein Bax, were evidently upregulated, while the expression levels in the Si-AURKA+inhibitor groups and the blank groups in both RT4 and T24 cells were similar (Fig. 7D). Collectively, miR-490-3p suppressed bladder cancer cell 
A

LINC00958 Target : 5' caGCA--AGAUAGCUCCAGGUUg 3'

miR-490-3p miRNA: 3' guCGUACCUCAGGAGGUCCAAc 5'

B

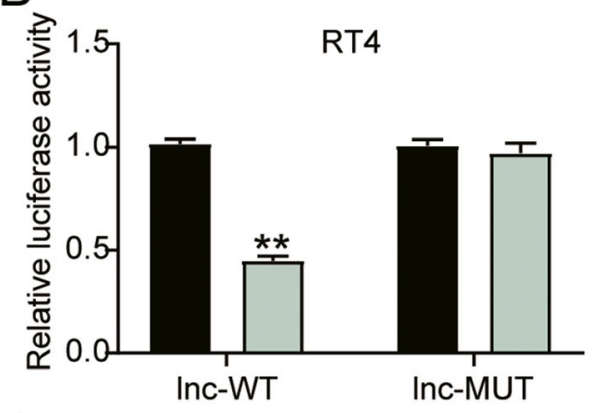

C
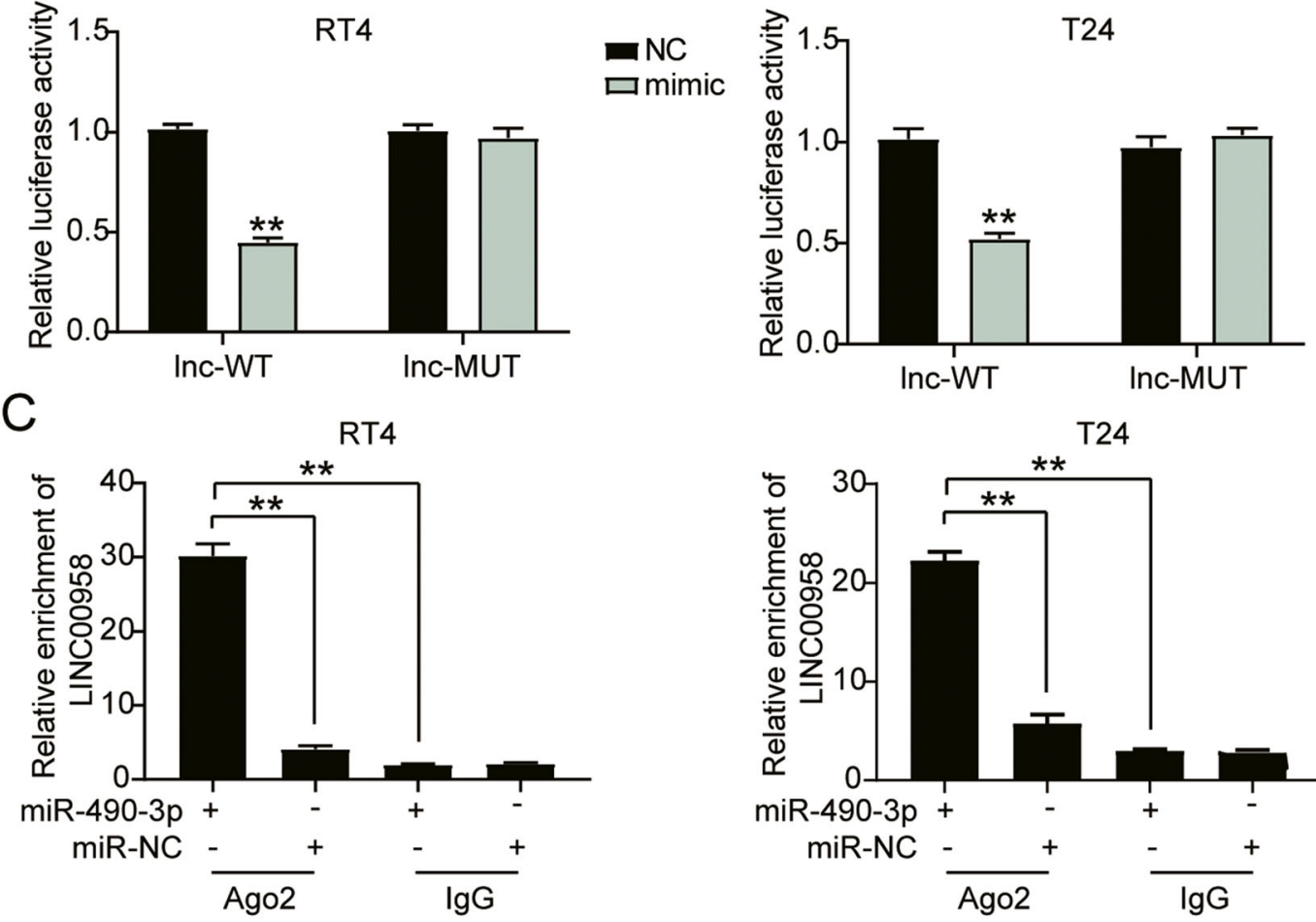

$\square \mathrm{NC}$

口mimic
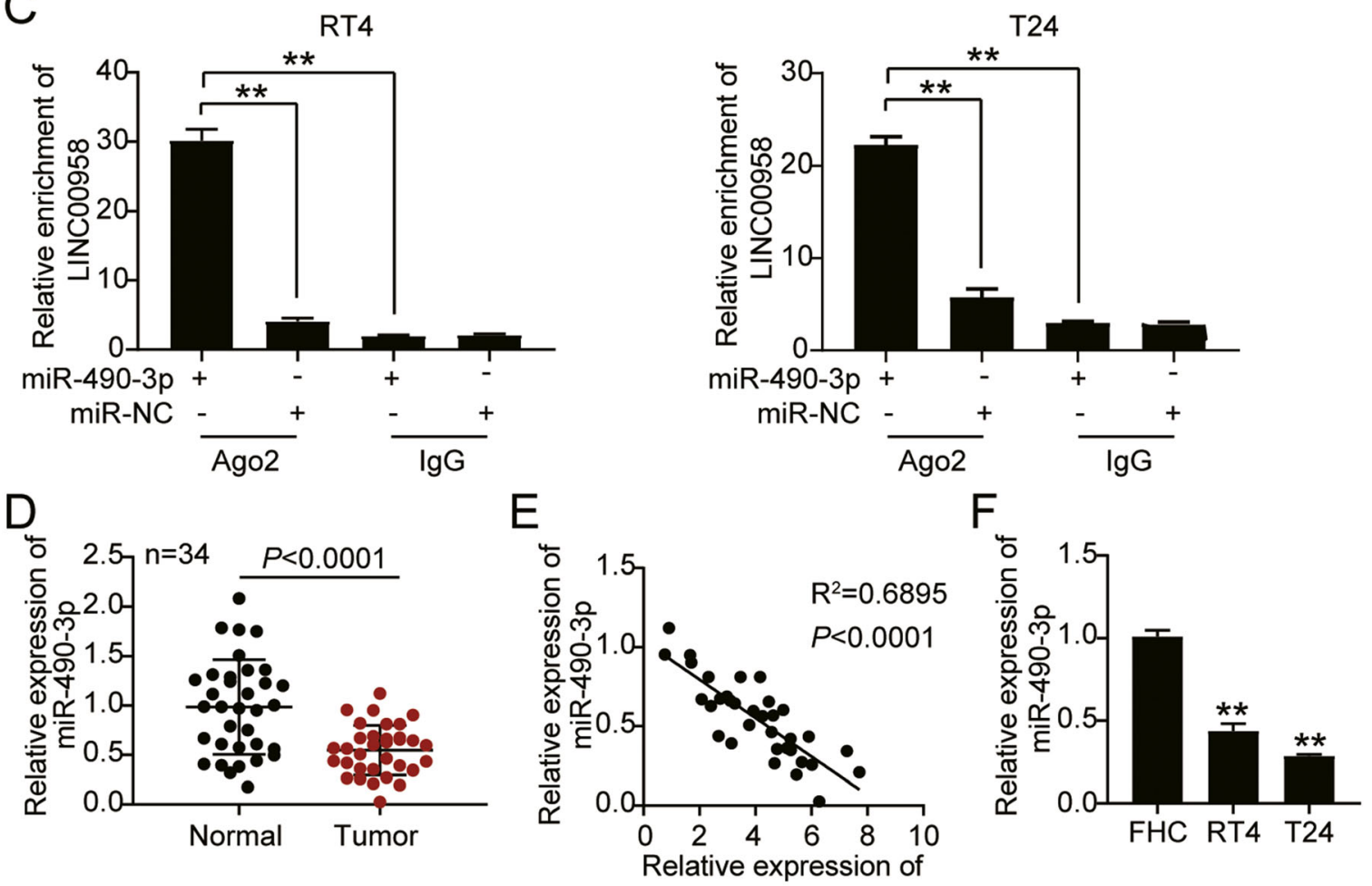

\section{G}

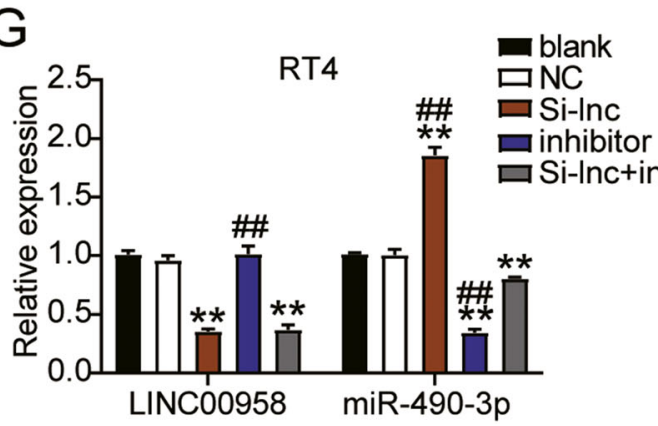

LINC00958

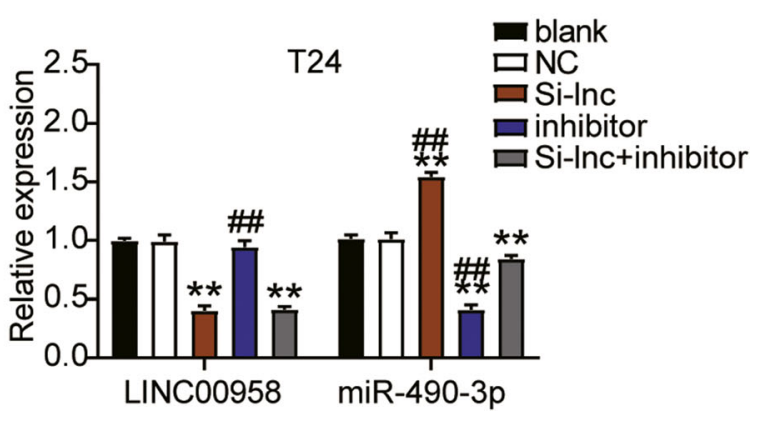

Fig. 4 (See legend on next page.) 
(See figure on previous page.)

Fig. 4 LINC00958 sponged miR-490-3p in bladder cancer cells. A TargetScan showed the predicted binding sequences of miR-490-3p for LINC00958. B Dual luciferase assay was performed in cells co-transfected with plasmids LINC00958-Wt or LINC00958-Mut and NC mimics or miR-490-3p mimic in RT4 and T24 cells. C RT-qPCR detection of LINC00958 expression on enrichment of miR-490-3p by RIP assay. D RT-qPCR detection of miR-490-3p expression in bladder cancer tissues $(n=34)$ and normal tissues $(n=34)$. E Correlation analysis between miR-490-3p expression and LINC00958 expression. F RT-qPCR detection of miR-490-3p expression in SV-HUC-1, RT4, and T24 cell lines. G RT-qPCR detection of LINC00958 and miR-490-3p expression in RT4 and T24 cells transfected with

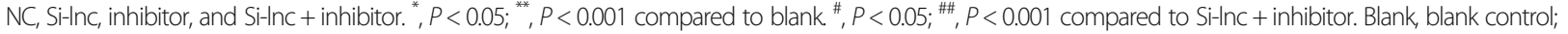
NC, negative control; Wt, wild-type; Mut, Mutant; Si-Inc, siRNA-LINC00958; inhibitor, miR-490-3p inhibitor

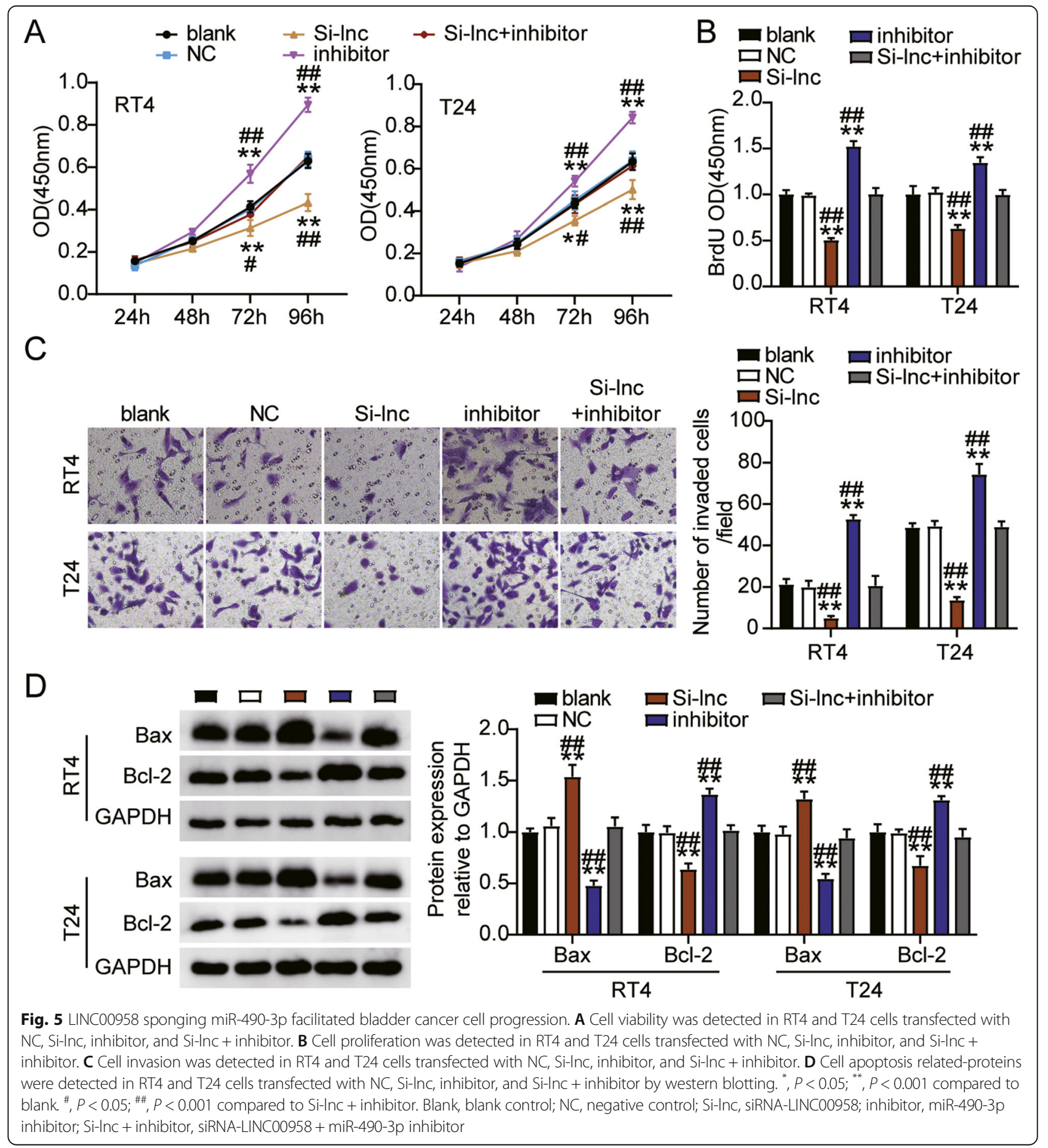




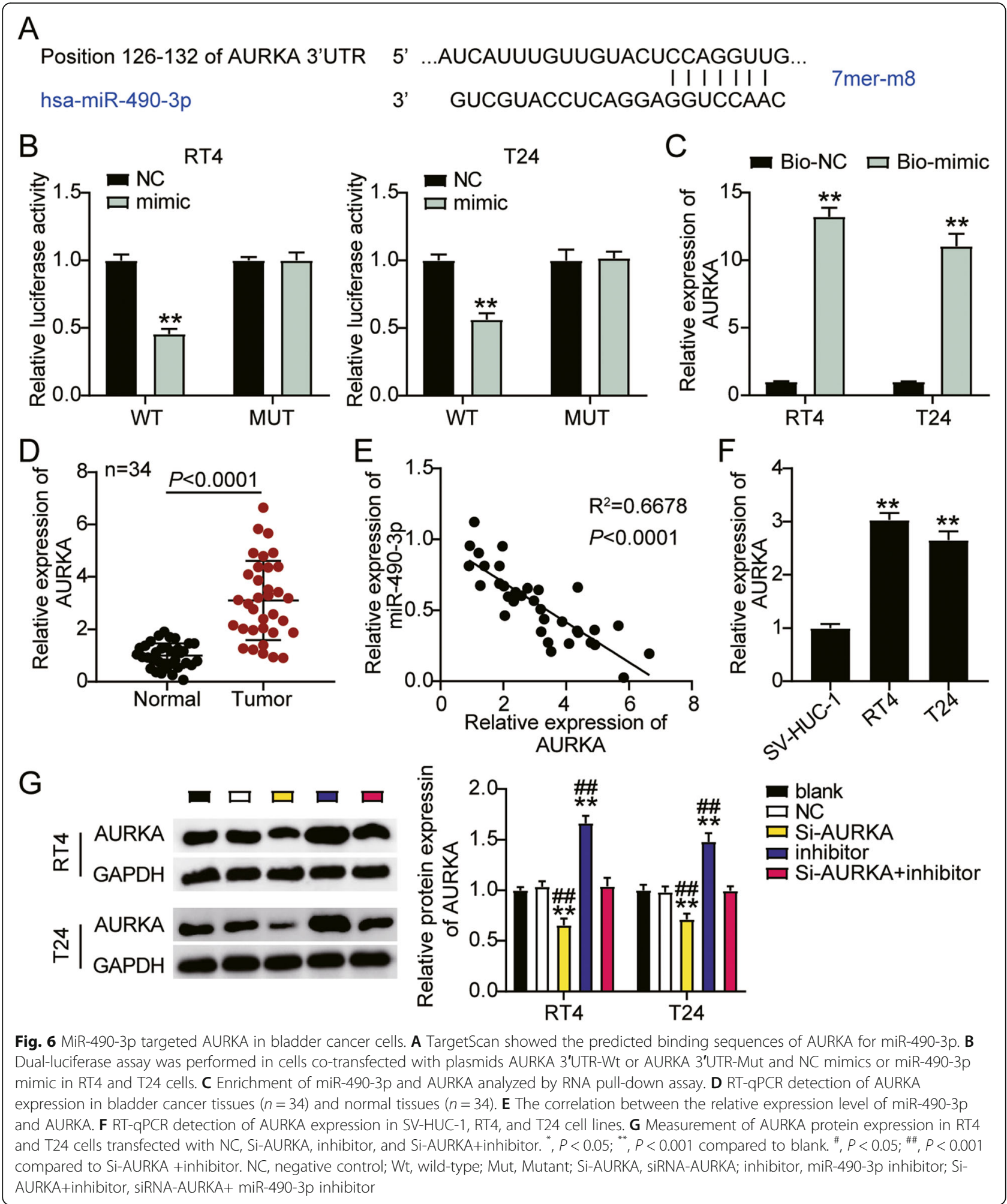




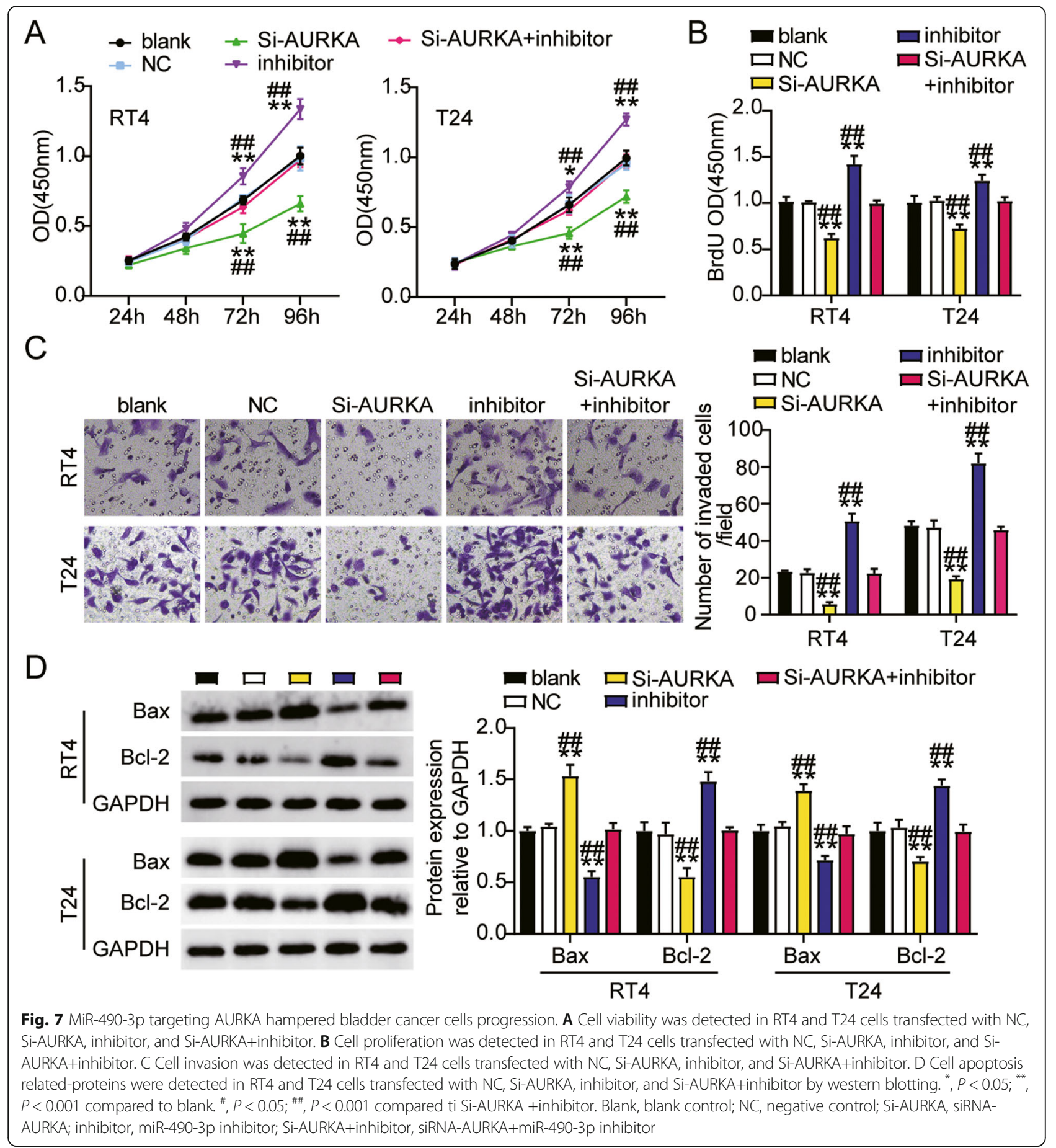

proliferation and invasion, while boosting cell apoptosis by targeting AURKA.

\section{Discussion}

Our study confirmed that the expression of LINC00958 and AURKA was upregulated in bladder cancer, while the expression of miR-490-3p was downregulated. Furthermore, LINC00958 enhanced cell growth and invasion, but suppressed apoptosis of bladder cancer cells by inhibiting miR-490-3p and upregulating AURKA expression. Thus, the LINC00958-miR-490-3p-AURKA axis may be an effective therapeutic strategy for bladder cancer.

An increasing number of studies have demonstrated the essential role of IncRNAs in bladder cancer development, such as lncRNA SNHG1, lncRNA DLX6-AS1, and 
lncRNA SNHG3. All these lncRNAs facilitate bladder cancer progression by enhancing cell growth and reducing cell apoptosis [47-49]. Furthermore, several studies have revealed that LINC00958 acts as an oncogenic driver in bladder cancer [14, 42, 50]. He et al. [42] demonstrated that LINC00958 promotes bladder cancerassociated lymphangiogenesis and lymphatic metastasis in vivo and in vitro. Another study revealed that silencing of LINC00958 attenuated bladder cancer progression by repressing miR-378a-3p and elevating IGF1R expression [14]. Consistent with these studies, we also found that LINC00958 was upregulated in bladder cancer tissues and cells, and LINC00958 promoted cell viability and invasion, but inhibited cell apoptosis in bladder cancer cells. Furthermore, our study showed that LINC00958 inhibited tumorigenesis in bladder cancer cells by suppressing miR-490-3p to upregulate AURKA, which was different from previous studies on LINC00958 in bladder cancer. Therefore, our study revealed a new axis involving LINC00958-miR-490-3pAURKA in the progression of bladder cancer.

Multiple studies have suggested that miR-490-3p acts as a suppressor in most cancers, including hepatocellular carcinoma, gastric cancer, and breast cancer [51-53]. In bladder cancer, evidence has shown that miR-490-5p inhibits proliferation via G1-phase arrest of bladder cancer by targeting c-Fos [24]. Another study also revealed that upregulation of miR-490-5p led to decreased EGFR expression, hampering cell invasion in bladder cancer cells [25]. miR-490-3p and miR-490-5p are members of the family of miR-490, but the role of miR-490-3p in bladder cancer is unknown. Our study investigated the role of miR-490-3p in bladder cancer and found an obvious downregulation of miR-490-3p expression in bladder cancer. Inhibition of miR-490-3p elevated cell growth and suppressed apoptosis in bladder cancer. Additionally, miR-490-3p, sponged by LINC00958, could regulate its target gene AURKA, thereby inhibiting the progression of bladder cancer. Our study is the first to elucidate the role of miR-490-3p in bladder cancer.

Dysregulation of AURKA has been found in numerous cancers, including lung, cervical, and renal cancers, showing that it can facilitate cell growth and invasion, but represses cell apoptosis [54-56]. As referred to bladder cancer, Guo et al. [33] reported that AURKA expression was significantly elevated in bladder cancer tissues, and the high expression of AURKA presented a poor prognosis. Another study indicated that AURKA targeted by miR-124-3p could enhance proliferation and migration and impair apoptosis of bladder cancer cells $[35,53]$. Consistent with previous reports, a similar molecular mechanism of AURKA in bladder cancer was revealed in our study; high level of AURKA was also observed in bladder cancer, and the downregulation of
AURKA could hamper bladder cancer progression. However, to investigate the mechanism of miR-490-3p/ AURKA on the proliferation, migration, and apoptosis of cancer cells, Si-AURKA and miR-490-3p inhibitor were transfected into RT4 and T24 cells. The results showed that cell proliferation and migration were increased and apoptosis was decreased after transfection with the miR490-3p inhibitor. In addition, Si-AURKA transfection inhibited cell proliferation and migration and promoted apoptosis. Therefore, we speculated that the effect of the inhibitor and Si-AURKA on the cancer cells was offset by each other. Hence, AURKA could be targeted by miR-490-3p to affect bladder cancer progression. Finally, we further elucidated that LINC00958 facilitated bladder cancer progression via the miR-490-3p/AURKA axis. Thus, this study is the first to report that AURKA could be regulated by both LINC00958 and miR-490-3p in bladder cancer progression.

As previously reported, evidence showed that lncRNA RP11-480I12.5 promotes the progression of breast cancer cells through the miR-490-3p-AURKA-Wnt/ $\beta$-catenin axis [53]. Therefore, whether the $\mathrm{Wnt} / \beta$-catenin pathway or other pathways participate in the LINC00958/miR-490-3p/AURKA axis in bladder cancer needs further exploration. Meanwhile, the role of the LINC00958/miR-490-3p/AURKA axis in bladder cancer also needs to be proven both in vivo and clinically. In addition, this study screened the differentially expressed miRNAs and mRNAs in bladder cancer using GEO DataSets, and the targets of LINC00958, miR-490-3p, and AURKA will be further explored in the future using multiple databases such as TCGA and GEPIA.

\section{Conclusions}

Taken together, our findings indicate that LINC00958 aggravates cell growth and invasion, but hampers apoptosis of bladder cancer cells via the miR-490-3p/AURKA axis. This may provide a new direction for the clinical treatment of bladder cancer patients.

\section{Abbreviations \\ AURKA: Aurora kinase A; Inc-WT: LINC00958-wide type; Inc-MUT: LINC00958 mutant; IncRNAs: long non-coding RNAs; miRNAs: microRNAs; NC: negative control; Si-Inc: siRNA-LINC00958; SD: standard deviation}

\section{Supplementary Information}

The online version contains supplementary material available at https://doi. org/10.1186/s12885-021-08882-6.

\section{Additional file 1.}

Acknowledgments

Not applicable.

Authors' contributions

QY performed the experiments and data analysis. HTZ and PD conceived and designed the study. XLT made the acquisition of data. TQW did the 
analysis and interpretation of data. All authors read and approved the manuscript.

\section{Funding}

Funding information is not available.

\section{Availability of data and materials}

The datasets used and/or analyzed during the current study are available from the corresponding author on reasonable request.

\section{Declarations}

\section{Ethics approval and informed consent}

The present study was approved by the Ethics Committee of Zhengzhou Central Hospital Affiliated to Zhengzhou University. The processing of clinical tissue samples is in strict compliance with the ethical standards of the Declaration of Helsinki. All patients signed written informed consent.

\section{Consent for publication}

Not applicable.

\section{Competing interests}

The authors declare that they have no competing interests.

\section{Author details}

'Department of Urology Ward 1, Zhengzhou Central Hospital Affiliated to Zhengzhou University, No. 195 Tongbai Road, Zhongyuan District, Zhengzhou 450007, Henan, China. ${ }^{2}$ Department of Urology, Peking University Cancer Hospital, Beijing 100142, China.

Received: 26 March 2021 Accepted: 19 September 2021 Published online: 26 October 2021

\section{References}

1. Bray F, Ferlay J, Soerjomataram I, Siegel RL, Torre LA, Jemal A. Global cancer statistics 2018: GLOBOCAN estimates of incidence and mortality worldwide for 36 cancers in 185 countries. CA Cancer J Clin. 2018;68(6):394-424. https://doi.org/10.3322/caac.21492.

2. Baughan DM, White-Baughan J, Pickwell S, Bartlome J, Wong S. Primary care needs of Cambodian refugees. J Fam Pract. 1990;30(5):565-8.

3. DeGeorge KC, Holt HR, Hodges SC. Bladder Cancer: diagnosis and treatment. Am Fam Physician. 2017;96(8):507-14

4. Yao M, Shi X, Li Y, Xiao Y, Butler W, Huang Y, et al. LINC00675 activates androgen receptor axis signaling pathway to promote castration-resistant prostate cancer progression. Cell Death Dis. 2020;11(8):638. https://doi.org/1 0.1038/s41419-020-02856-5.

5. Gong X, Dong T, Niu M, Liang X, Sun S, Zhang Y, et al. IncRNA LCPAT1 upregulation promotes breast Cancer progression via enhancing MFAP2 transcription. Mol Ther Nucleic Acids. 2020;21:804-13. https://doi.org/10.101 6/j.omtn.2020.07.015.

6. Shu J, Wang D. Functional characterization of the long noncoding RNA MIR22HG as a tumour suppressor in cervical cancer by targeting IGF2BP2. Eur Rev Med Pharmacol Sci. 2020;24(15):7953-62. https://doi.org/10.26355/ eurrev_202008_22478.

7. Ma L, Cao J, Liu L, Du Q, Li Z, Zou D, et al. LncBook: a curated knowledgebase of human long non-coding RNAs. Nucleic Acids Res. 2019; 47(D1):D128-d134. https://doi.org/10.1093/nar/gky960.

8. Wang X, Chen Q, Wang X, Li W, Yu G, Zhu Z, et al. ZEB1 activated-VPS9D1AS1 promotes the tumorigenesis and progression of prostate cancer by sponging miR-4739 to upregulate MEF2D. Biomed Pharmacother. 2020;122: 109557. https://doi.org/10.1016/j.biopha.2019.109557.

9. Yao L, Chen L, Zhou H, Duan F, Wang L, Zhang Y. Long noncoding RNA NEAT1 promotes the progression of breast Cancer by regulating miR-1385p/ZFX Axis. Cancer Biother Radiopharm. 2020. https://doi.org/10.1089/cbr.2 019.3515.

10. Wang S, Cheng Y, Yang P, Qin G. Silencing of long noncoding RNA LINC00324 interacts with MicroRNA-3200-5p to attenuate the tumorigenesis of gastric Cancer via regulating BCAT1. Gastroenterol Res Pract. 2020;2020: 4159298-12. https://doi.org/10.1155/2020/4159298.

11. Zhao H, Zheng GH, Li GC, Xin L, Wang YS, Chen Y, et al. Long noncoding RNA LINC00958 regulates cell sensitivity to radiotherapy through RRM2 by binding to microRNA-5095 in cervical cancer. J Cell Physiol. 2019;234(12): 23349-59. https://doi.org/10.1002/jcp.28902.

12. Luo Z, Han Z, Shou F, Li Y, Chen Y. LINC00958 accelerates cell proliferation and migration in non-small cell lung Cancer through JNK/c-JUN signaling. Hum Gene Ther Methods. 2019;30(6):226-34. https://doi.org/10.1089/hgtb.2 019.115.

13. Wang W, Song ZJ, Wang Y, Zhong WF, Kang P, Yang Y. Elevated long noncoding RNA LINC00958 was associated with metastasis and unfavorable prognosis in gastric cancer. Eur Rev Med Pharmacol Sci. 2019;23(2):598-603. https://doi.org/10.26355/eurrev_201901_16872.

14. Cui Y, Xie M, Zhang Z. LINC00958 involves in bladder Cancer through sponging miR-378a-3p to elevate IGF1R. Cancer Biother Radiopharm. 2020; 35(10):776-88. https://doi.org/10.1089/cbr.2019.3300.

15. Di Leva G, Garofalo M, Croce CM. MicroRNAs in cancer. Annu Rev Pathol. 2014:9(1):287-314. https://doi.org/10.1146/annurev-pathol-012513-104715.

16. Wang M, Yang M, Deng B. miR-548a-3p weakens the tumorigenesis of Colon Cancer through targeting TPX2. Cancer Biother Radiopharm. 2020. https://doi.org/10.1089/cbr.2020.3767.

17. Li H, Xu Y, Zhao D. MicroRNA-193b regulates human ovarian cancer cell growth via targeting STMN1. Exp Ther Med. 2020;20(4):3310-5. https://doi. org/10.3892/etm.2020.9033.

18. Zhou JS, Yang ZS, Cheng SY, Yu JH, Huang CJ, Feng Q. miRNA-425-5p enhances lung cancer growth via the PTEN/PI3K/AKT signaling axis. BMC Pulm Med. 2020;20(1):223. https://doi.org/10.1186/s12890-020-01261-0.

19. Wang H, Yang G, Yu Y, Gu P. MicroRNA-490-3p suppresses the proliferation and invasion of hepatocellular carcinoma cells via targeting TMOD3. Oncol Lett. 2020;20(4):95. https://doi.org/10.3892/ol.2020.11956.

20. Liu W, Yin C, Liu Y. Circular RNA circ_0091579 promotes hepatocellular carcinoma proliferation, migration, invasion, and glycolysis through miR490-5p/CASC3 Axis. Cancer Biother Radiopharm. 2020. https://doi.org/10.1 089/cbr.2019.3472.

21. Fan H. Zhang YS: miR-490-3p modulates the progression of prostate cancer through regulating histone deacetylase 2. Eur Rev Med Pharmacol Sci. 2019; 23(2):539-46. https://doi.org/10.26355/eurrev_201901_16866.

22. Pan Z, Lin J, Wu D, He X, Wang W, Hu X, et al. Hsa_circ_0006948 enhances cancer progression and epithelial-mesenchymal transition through the miR490-3p/HMGA2 axis in esophageal squamous cell carcinoma. Aging. 2019; 11(24):11937-54. https://doi.org/10.18632/aging.102519.

23. Fan H, Yuan J, Li X, Ma Y, Wang X, Xu B, et al. LncRNA LINC00173 enhances triple-negative breast cancer progression by suppressing miR-490-3p expression. Biomed Pharmacother. 2020;125:109987.

24. Li S, Xu X, Xu X, Hu Z, Wu J, Zhu Y, et al. MicroRNA-490-5p inhibits proliferation of bladder cancer by targeting c-Fos. Biochem Biophys Res Commun. 2013;441(4):976-81. https://doi.org/10.1016/j.bbrc.2013.11.006.

25. Wu L, Zhang M, Qi L, Zu X, Li Y, Liu L, et al. ERa-mediated alterations in circ_0023642 and miR-490-5p signaling suppress bladder cancer invasion. Cell Death Dis. 2019:10(9):635. https://doi.org/10.1038/s41419-019-1827-3.

26. Lan G, Yang L, Xie X, Peng L, Wang Y. MicroRNA-490-5p is a novel tumor suppressor targeting c-FOS in human bladder cancer. Arch Med Sci. 2015: 11(3):561-9. https://doi.org/10.5114/aoms.2015.52359.

27. Ommer J, Selfe JL, Wachtel M, O'Brien EM, Laubscher D, Roemmele M, et al. Aurora a kinase inhibition destabilizes PAX3-FOXO1 and MYCN and synergizes with Navitoclax to induce rhabdomyosarcoma cell death. Cancer Res. 2020;80(4):832-42. https://doi.org/10.1158/0008-5472.CAN-19-1479.

28. Bertolin G, Tramier M. Insights into the non-mitotic functions of Aurora kinase a: more than just cell division. Cell Mol Life Sci. 2020;77(6):1031-47. https://doi.org/10.1007/s00018-019-03310-2.

29. Zhou W, Wu J, Liu X, Ni M, Meng Z, Liu S, et al. Identification of crucial genes correlated with esophageal cancer by integrated high-throughput data analysis. Medicine. 2020;99(20):e20340. https://doi.org/10.1097/MD. 0000000000020340

30. Nieto-Jimenez C, Galan-Moya EM, Corrales-Sanchez V, Noblejas-Lopez MDM, Burgos M, Domingo B, et al. Inhibition of the mitotic kinase PLK1 overcomes therapeutic resistance to $\mathrm{BET}$ inhibitors in triple negative breast cancer. Cancer Lett. 2020;491:50-9. https://doi.org/10.1016/j.canlet.2020.06.020.

31. Thaiparambil J, Dong L, Jasso D, Huang JA, El-Zein RA. Mitotic Spindle Apparatus Abnormalities in Chronic Obstructive Pulmonary Disease Cells: A Potential Pathway to Lung Cancer. Cancer Prev Res (Philadelphia, Pa). 2020; 13(11):923-34

32. Burgess EF, Livasy C, Trufan S, Hartman A, Guerreri R, Naso C, et al. High aurora kinase expression identifies patients with muscle-invasive bladder 
cancer who have poor survival after neoadjuvant chemotherapy. Urol Oncol. 2019;37(12):900-6. https://doi.org/10.1016/j.urolonc.2019.09.009

33. Guo $M$, Lu S, Huang $H$, Wang $Y$, Yang $M Q$, Yang $Y$, et al. Increased AURKA promotes cell proliferation and predicts poor prognosis in bladder cancer. BMC Syst Biol. 2018;12(Suppl 7):118. https://doi.org/10.1186/s12918-0180634-2.

34. Mobley A, Zhang S, Bondaruk J, Wang Y, Majewski T, Caraway NP, et al. Aurora kinase $\mathrm{a}$ is a biomarker for bladder Cancer detection and contributes to its aggressive behavior. Sci Rep. 2017;7(1):40714. https://doi.org/10.1038/ srep40714.

35. Yuan $Q$, Sun T, Ye F, Kong W, Jin H. MicroRNA-124-3p affects proliferation, migration and apoptosis of bladder cancer cells through targeting AURKA Cancer Biomark. 2017;19(1):93-101. https://doi.org/10.3233/CBM-160427.

36. Chen M, Xu Z, Zhang Y, Zhang X. LINC00958 promotes the malignancy of nasopharyngeal carcinoma by sponging microRNA-625 and thus upregulating NUAK1. OncoTargets Ther. 2019;12:9277-90. https://doi.org/1 $0.2147 / O T T . S 216342$.

37. Huang S, Zhan Z, Li L, Guo H, Yao Y, Feng M, et al. LINC00958-MYC positive feedback loop modulates resistance of head and neck squamous cell carcinoma cells to chemo- and radiotherapy in vitro. OncoTargets Ther. 2019:12:5989-6000. https://doi.org/10.2147/OT.S208318.

38. Chen F, Liu M, Yu Y, Sun Y, Li J, Hu W, et al. LINC00958 regulated miR-627$5 \mathrm{p} / \mathrm{YBX} 2$ axis to facilitate cell proliferation and migration in oral squamous cell carcinoma. Cancer Biol Ther. 2019;20(9):1270-80. https://doi.org/10.1 080/15384047.2019.1617571.

39. Wang L, Zhong Y, Yang B, Zhu Y, Zhu X, Xia Z, et al. LINC00958 facilitates cervical cancer cell proliferation and metastasis by sponging miR-625-5p to upregulate LRRC8E expression. J Cell Biochem. 2020;121(3):2500-9. https:// doi.org/10.1002/jcb.29472.

40. Seitz AK, Christensen LL, Christensen E, Faarkrog K, Ostenfeld MS, Hedegaard J, et al. Profiling of long non-coding RNAs identifies LINC00958 and LINC01296 as candidate oncogenes in bladder cancer. Sci Rep. 2017; 7(1):395. https://doi.org/10.1038/s41598-017-00327-0.

41. Yazarlou F, Modarressi MH, Mowla SJ, Oskooei VK, Motevaseli E, Tooli LF, et al. Urinary exosomal expression of long non-coding RNAs as diagnostic marker in bladder cancer. Cancer Manag Res. 2018;10:6357-65. https://doi. org/10.2147/CMAR.S186108.

42. He W, Zhong G, Jiang N, Wang B, Fan X, Chen C, et al. Long noncoding RNA BLACAT2 promotes bladder cancer-associated lymphangiogenesis and lymphatic metastasis. J Clin Invest. 2018;128(2):861-75. https://doi.org/10.11 72/JCl96218.

43. Kang NN, Ge SL, Zhang RQ, Huang YL, Liu SD, Wu KM. MiR-490-3p inhibited the proliferation and metastasis of esophageal squamous cell carcinoma by targeting HMGA2. Eur Rev Med Pharmacol Sci. 2018;22(23):8298-305. https://doi.org/10.26355/eurrev_201812_16527.

44. Liu X, He B, Xu T, Pan Y, Hu X, Chen X, et al. MiR-490-3p functions as a tumor suppressor by inhibiting oncogene VDAC1 expression in colorectal Cancer. J Cancer. 2018;9(7):1218-30. https://doi.org/10.7150/jca.23662.

45. Zhang F, Wu A, Wang Y, Liu J. miR-490-3p functions as a tumor suppressor in glioma by inhibiting high-mobility group AT-hook 2 expression. Exp Ther Med. 2019;18(1):664-70. https://doi.org/10.3892/etm.2019.7606.

46. Zabihula B, Yiliyasi M, Lu Y, Salai A. MicroRNA-490-3p inhibits proliferation and stimulates apoptosis of ESCC cells via MAPK1 downregulation. Oncol Lett. 2019;18(3):3170-6. https://doi.org/10.3892/ol.2019.10636.

47. Xiang W, Lyu L, Huang T, Zheng F, Yuan J, Zhang C, et al. The long noncoding RNA SNHG1 promotes bladder cancer progression by interacting with miR-143-3p and EZH2. J Cell Mol Med. 2020;24(20):11858-73. https:// doi.org/10.1111/jcmm.15806.

48. Wang $H$, Niu $X$, Jiang $H$, Mao F, Zhong $B$, Jiang $X$, et al. Long non-coding RNA DLX6-AS1 facilitates bladder cancer progression through modulating miR-195-5p/NEGFA signaling pathway. Aging. 2020;12(16):16021-34. https:// doi.org/10.18632/aging.103374.

49. Dai G, Huang C, Yang J, Jin L, Fu K, Yuan F, et al. LncRNA SNHG3 promotes bladder cancer proliferation and metastasis through miR-515-5p/GINS2 axis. J Cell Mol Med. 2020;24(16):9231-43. https://doi.org/10.1111/jcmm.15564.

50. Yang L, Xu L, Wang $Q$, Wang M, An G. Dysregulation of long non-coding RNA profiles in human colorectal cancer and its association with overall survival. Oncol Lett. 2016;12(5):4068-74. https://doi.org/10.3892/ol.2016.5138.

51. Zhang H, Bao J, Zhao S, Huo Z, Li B. MicroRNA-490-3p suppresses hepatocellular carcinoma cell proliferation and migration by targeting the aurora kinase a gene (AURKA). Arch Med Sci. 2020;16(2):395-406. https://doi. org/10.5114/aoms.2019.91351.

52. Luo M, Liang C. LncRNA LINC00483 promotes gastric cancer development through regulating MAPK1 expression by sponging miR-490-3p. Biol Res. 2020;53(1):14. https://doi.org/10.1186/s40659-020-00283-6.

53. Gao X, Lai Y, Zhang Z, Ma Y, Luo Z, Li Y, et al. Long Non-coding RNA RP11480112.5 Promotes the Proliferation, Migration, and Invasion of Breast Cancer Cells Through the miR-490-3p-AURKA-Wnt/B-Catenin Axis. Front Oncol. 2020;10:948.

54. Ma ZL, Zhang BJ, Wang DT, Li X, Wei JL, Zhao BT, et al. Tanshinones suppress AURKA through up-regulation of miR-32 expression in non-small cell lung cancer. Oncotarget. 2015;6(24):20111-20. https://doi.org/10.18632/ oncotarget.3933.

55. Shao S, Wang C, Wang S, Zhang H, Zhang Y. Hsa_circ_0075341 is upregulated and exerts oncogenic properties by sponging miR-149-5p in cervical cancer. Biomed Pharmacother. 2020;121:109582. https://doi.org/10.1 016/j.biopha.2019.109582.

56. Kulkarni P, Dasgupta P, Bhat NS, Shahryari V, Shiina M, Hashimoto Y, et al. Elevated miR-182-5p associates with renal Cancer cell mitotic arrest through diminished MALAT-1 expression. Mol Cancer Res. 2018;16(11):1750-60. https://doi.org/10.1158/1541-7786.MCR-17-0762.

\section{Publisher's Note}

Springer Nature remains neutral with regard to jurisdictional claims in published maps and institutional affiliations.

\section{Ready to submit your research? Choose BMC and benefit from:}

- fast, convenient online submission

- thorough peer review by experienced researchers in your field

- rapid publication on acceptance

- support for research data, including large and complex data types

- gold Open Access which fosters wider collaboration and increased citations

- maximum visibility for your research: over $100 \mathrm{M}$ website views per year

At BMC, research is always in progress.

Learn more biomedcentral.com/submissions 